\title{
Matérista
}

Revista Matéria, v. 14, n.2, pp. 824 - 844, 2009

ISSN 1517-7076

http://www.materia.coppe.ufrj.br/sarra/artigos/artigo11076

\section{Caracterização mecânica das argamassas de assentamento para alvenaria estrutural - previsão e modo de ruptura}

\author{
MOHAMAD, G. ${ }^{\text {I }}$ NETO, A.B.da S.S. ${ }^{\text {I }}$ PELISSER F. ${ }^{\text {II }}$ LOURENÇO, P.B. ${ }^{\text {III }}$; ROMAN, H.R. ${ }^{\text {IV }}$ \\ IUniversidade Federal do Pampa - UNIPAMPA - Av. Tiarajú, 810, Bairro Ibirapuitã - CEP 97546-550, \\ Alegrete, RS. \\ e-mail: gihad@unesc.net, almir@unipampa.edu.br \\ IIUniversidade do Extremo Sul Catarinense - UNESC - Av. Universitária, 1105 - Bairro Universitário - C.P. \\ 3167 - CEP.: 88806-000, Criciúma, SC. \\ e-mail: fep@unesc.net \\ III Universidade do Minho - Escola de Engenharia, Campus de Azurém - CEP: 4800-058, Guimarães. \\ e-mail: pbl@civil.uminho.pt \\ ${ }^{\mathrm{IV}}$ Universidade Federal de Santa Catarina - UFSC - R. João Pio Duarte da Silva, 205 - Bairro Córrego \\ Grande - CEP.: 88040-970 Florianópolis, SC. \\ e-mail: humberto@ecv.ufsc.br
}

\section{RESUMO}

Este trabalho pretende avaliar o comportamento mecânico das argamassas de assentamento para o uso estrutural, por meio das propriedades de resistência à compressão, tração na flexão e módulo de elasticidade, sob estados de tensões uniaxial e multiaxial. Portanto, estabelecer correlações entre os resultados mecânicos de diferentes traços de argamassas, relações água/cimento e geometria da amostra associada ao modo de ruptura. As principais conclusões obtidas, entre outras, são: existe uma relação potencial entre a resistência a compressão da amostra de geometria cúbica, cilíndrica e a resistência à flexão (amostra de geometria prismática) em função da relação água/cimento; a função linear é a que melhor ajusta os valores médios do módulo de elasticidade em função da resistência à compressão; a envoltória de ruptura da argamassa confinada lateralmente pode ser representada como uma relação linear de Mohr-Coulomb; observou-se, por meio de ensaios de microscopia eletrônica de varredura a existência de fissuras de retração na interface pasta-agregado e poros isolados, devido ao fluxo ascendente de água causado pela exsudação.

Palavras chaves: argamassa de assentamento, resistência á compressão uniaxial e triaxial, módulo de elasticidade.

\section{Mechanical behaviour of bedding mortar for structural masonry - preview and failure mode}

\section{ABSTRACT}

This paper presents the mechanical behaviour of hardening mortars for structural masonry, regarding compressive strength, flexural strength and elasticity modulus under uniaxial and triaxial stress state. One has used casting cubic, prism and cylindrical specimens. The conclusions drawn from the present studies are: there is a potential relation between compressive strength of cube, cylinders and flexural strength with water/cement ratio; there is a linear relation between elasticity modulus and compressive strength of mortar; the ultimate strength envelope can be represented by a linear function; It is possible to observe the macropores with dispersed cracks in the transition zone between paste and grain, the cracks seems to be induced by shrinkage and weeping; mortars exhibits high porosity and different sizes of voids, with a possible initial decrease in volume by closing of the flaw and voids; the constitutive model to represent the non-linear elasticity of mortar was proposed.

Keywords: bedding mortar, uniaxial and triaxial compressive strength, elasticity modulus. 


\section{INTRODUÇÃO}

A alvenaria estrutural é um dos sistemas construtivo comumente empregado em países como o Brasil, devido à facilidade de execução e economia proporcionadas. Essas vantagens tornam este tipo de sistema mais competitivo em relação aos demais.

As alvenarias são compostas pela justaposição entre o bloco e a argamassa, cujas combinações entre as diferentes características mecânicas dos materiais foram estudadas por diversos pesquisadores em diferentes épocas. Como exemplo, pode-se citar em ordem cronológica os trabalhos de DRYSDALE e HAMID [1]], McNARY [2]], CHEEMA e KLINGNER [3]], KHALAF et al. [4]], VERMELTFOORT [ㅁ] e MOHAMAD et al. [6]. Essas pesquisas, de uma forma geral, indicam que na alvenaria deve haver uma compatibilidade nas características mecânicas entre os tipos de bloco e a capacidade resistente da argamassa de assentamento. As formas de ruptura observadas nos ensaios de paredes, ocorrem por indução de tensões de tração no bloco ou por esmagamento da junta de assentamento da argamassa. Estudos realizados por SHRIVE [7] mostraram que a ruptura da alvenaria sob compressão é a mesma de qualquer material frágil como o concreto, o vidro e a pedra. Ou seja, as fissuras têm início nos vazios do material, onde as tensões de tração lateral localizadas são maiores do que as tensões médias obtidas em testes realizados em laboratórios. Durante os ensaios experimentais em alvenarias, realizados por VERMELTFOORT [5] e MOHAMAD et al. [] ], também se observou que o processo de ruptura da alvenaria acontecia inicialmente pelo esmagamento da junta de argamassa e o posterior esfacelamento da superfície de contato entre o bloco e a argamassa, como mostra a Figura 1.



Figura 1: Ruptura do conjunto bloco e argamassa observada nos ensaios experimentais.

Com base nos estudos de KHALAF et al. [4] pode-se concluir que é difícil estabelecer modelos que representem a resistência da alvenaria a partir das proporções entre os valores de resistência dos materiais individualmente. Ensaios experimentais de compressão em prismas evidenciaram que a resistência se aproxima mais ao bloco, quanto mais baixo for a proporção entre os módulos de elasticidade dos materiais

(argamassa, $E_{\text {arg }}$ e bloco, $E_{\text {bloco}}$ ). Por outro lado, a medida que essa proporção aumenta, para níveis entre 0,8 e 1, a resistência do prisma começa a se aproximar da argamassa. Em função disso, é possível deduzir que o princípio da sobreposição de resistências entre os materiais só é válido para certo grupo, não podendo ser generalizado para todas as demais combinações de materiais. A ruptura da alvenaria (bloco e argamassa) acontece devido à perda de coesão da argamassa e por atingir a tensão limite de cisalhamento gerado, por conseqüência, do "poro colapso" da estrutura interna da argamassa. Neste contexto, o objetivo principal deste trabalho é caracterizar física e mecanicamente as argamassas de assentamento a base de cal, para o uso estrutural, determinando as respectivas correspondências entre os valores destas propriedades físicas e mecânicas, servindo assim de referência aos projetistas para a utilização no dimensionamento da alvenaria.

Existem poucas informações sobre as argamassas de assentamento para as alvenarias estruturais de forma a caracterizar a relação água/cimento $(a / c)$, a geometria da amostra (cubos ou cilindros), os índices de vazios e o módulo de elasticidade. Em virtude deste fato foram utilizadas nesta pesquisa diferentes proporções entre o cimento, a cal e a areia, formas geométricas e modos de determinação do módulo de elasticidade, sob estados de tensões uniaxial e triaxial. Os traços designados na pesquisa seguem as recomendações das normas inglesa BS-5628 [ㅇ] e americana ASTM C-270 [ㅁ]. 


\section{MATERIAIS E MÉTODOS}

A alvenaria estrutural é atualmente um dos sistemas construtivos que vem sendo amplamente empregado como alternativa a técnica convencional do concreto armado. O parâmetro que define o potencial de suporte de carga de um elemento estrutural em alvenaria estrutural é a resistência à compressão da parede, que de certa forma, está condicionada às características da unidade e da argamassa empregada. Portanto, este trabalho tem como objetivo principal caracterizar mecanicamente as argamassas de assentamentos, recomendada pela BS-5628[8].

\subsection{Propriedades Físicas e Mecânicas das Argamassas de Assentamento}

Os itens a seguir descrevem os requisitos físicos e mecânicos especificados pelas normas NBR 7211

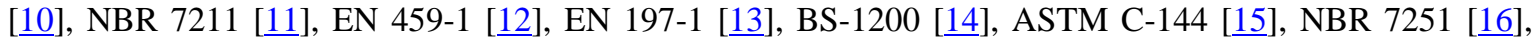
NBR 9778 [17], ASTM C-270 [ㅁ] e BS-5628 [ㅁ], para as argamassas de assentamento.

\subsubsection{Especificação da granulométrica da areia}

Os ensaios de caracterização física servem de base para o cálculo das percentagens de material em massa, que farão parte das composições das argamassas. Permitindo desta maneira definir as faixas de variação dos tamanhos dos grãos de agregados, a partir dos limites granulométricos fixados pelas normalizações. Neste contexto, pretende-se utilizar as designações especificadas pelas normas NBR 7211 [10], NBR 7211 [11], BS-1200 [14] e ASTM C-144 [15] para caracterizar a composição granulométrica da areia para o uso em assentamento nas alvenarias. As normas BS-1200 [14] e ASTM C-144 [15] especificam as percentagens passantes das areias em função das peneiras, estabelecendo os limites granulométricos inferiores (LI) e superiores (LS), adequados para o uso em argamassas de assentamento, ver Tabela 1.

Tabela 1: Percentagens passantes de areia nas peneiras.

\begin{tabular}{c|c|c|c|c}
\hline \multirow{2}{*}{$\begin{array}{c}\text { Peneira } \\
\text { (abertura em mm) }\end{array}$} & \multicolumn{4}{|c}{ Percentagem passante (\%) } \\
\cline { 2 - 5 } & BS-1200 [14] & \multicolumn{2}{c}{ ASTM C-144 [15] } \\
\cline { 2 - 5 } & LI & LS & LI & LS \\
\hline 0,15 & 0 & 10 & 2 & 15 \\
0,30 & 5 & 40 & 10 & 35 \\
0,60 & 40 & 80 & 40 & 75 \\
1,20 & 70 & 100 & 70 & 100 \\
2,40 & 90 & 100 & 95 & 100 \\
4,80 & 100 & 100 & 100 & 100 \\
\hline
\end{tabular}

A NBR 7211 [10] fixa os limites granulométricos do agregado miúdo por meio das zonas em que o mesmo se enquadra. As denominações são apresentadas na Tabela 2, sendo essa caracterização em função das percentagens retidas de material nas respectivas peneiras.

O resultado da análise granulométrica da areia utilizada na confecção das argamassas encontra-se apresentado na Tabela 3. As percentagens retidas e passantes acumuladas foram obtidas pela média de duas porções de areia.

A areia empregada no programa experimental encontra-se dentro dos limites das percentagens passantes nas respectivas peneiras da série, quando utilizada as normas internacionais BS-1200 [14] e ASTM C-144 [15]. Por outro lado, ao usar como referência a norma NBR 7211 [10] a areia se encontra entre as zonas 2 e 3, ou seja, pode ser caracterizada em relação ao tamanho dos grãos como: finos e médios. A diferença principal entre as duas versões das normas NBR 7211 [10] e NBR 7211 [11] é a mudança nas denominações existentes. A segunda versão somente utiliza as denominações ótimas e utilizáveis, o que de certa forma se aplica apenas ao concreto. A primeira versão permitia a adequação da areia para outros fins como assentamento de alvenarias e revestimentos de paredes, pois existia uma faixa de variação por zonas, permitindo a classificação da areia conforme o tamanho do grão (muito fina, fina, média e grossa). O módulo de finura da areia é definido como o somatório das percentagens retidas acumuladas nas peneiras da série normal, até a abertura de peneira igual a $0,15 \mathrm{~mm}$ divididos por cem (100). O valor obtido para o módulo de finura da areia utilizada nos experimentos foi de 2,27. A dimensão máxima característica da areia é uma grandeza associada a distribuição granulométrica do agregado, correspondente à abertura de malha, nos quais 
as percentagens retidas acumuladas são iguais ou imediatamente inferiores a 5 \% em massa. A dimensão máxima característica da areia empregada nos experimentos foi igual a 2,4 mm.

Tabela 2: Limites granulométricos do agregado miúdo, NBR 7211 [10].

\begin{tabular}{c|c|c|c|c}
\hline \multirow{2}{*}{ Peneira (abertura em mm) } & \multicolumn{4}{|c}{ Percentagem, em massa, retida nas peneiras (\%) } \\
\cline { 2 - 5 } & Zona 1 & Zona 2 & Zona 3 & Zona 4 \\
\cline { 2 - 5 } & Muito fina & Fina & Média & Grossa \\
\hline 9,5 & 0 & 0 & 0 & 0 \\
6,3 & $0-3$ & $0-7$ & $0-7$ & $0-7$ \\
4,8 & $0-5^{*}$ & $0-10$ & $0-11$ & $0-12$ \\
2,4 & $0-5^{*}$ & $0-15^{*}$ & $0-25^{*}$ & $5^{*}-40$ \\
1,2 & $0-10^{*}$ & $0-25^{*}$ & $10^{*}-45^{*}$ & $30^{*}-70$ \\
0,6 & $0-20$ & $21-40$ & $41-65$ & $66-85$ \\
0,3 & $50-85^{*}$ & $60 *-85^{*}$ & $70^{*}-92$ & $80^{*}-95$ \\
0,15 & $85^{*}-100$ & $90^{* *}-100$ & $90^{* *}-100$ & $90 * *-100$ \\
\hline
\end{tabular}

*Tolerância de até 5\%;** Para agregado miúdo resultante de britagem este limite poderá ser de 80\%.

Tabela 3: Caracterização granulométrica da areia para os ensaios de argamassas.

\begin{tabular}{c|c|c}
\hline $\begin{array}{c}\text { Peneira } \\
\text { (abertura em mm) }\end{array}$ & $\begin{array}{c}\text { Percentagem retida } \\
\text { acumulada (\%) }\end{array}$ & $\begin{array}{c}\text { Percentagem passante } \\
\text { Acumulada (\%) }\end{array}$ \\
\hline 4,8 & 0 & 100 \\
2,4 & 7 & 93 \\
1,2 & 20 & 80 \\
0,6 & 36 & 64 \\
0,3 & 74 & 26 \\
0,15 & 90 & 10 \\
0,075 & 98 & 2 \\
Fundo & 100 & 0 \\
\hline
\end{tabular}

\subsubsection{Características da areia, cal e cimento}

De maneira geral, nas argamassas de assentamento para alvenaria estrutural, podem ser usados cimentos dos tipos portland comum, composto, pozolânico ou alto-forno. Nesta pesquisa foram utilizados nos experimentos cimento portland de calcário do tipo CEM II/B-L, de resistência a compressão não inferior a 32,5 MPa, conforme classificação da EN 197-1 [티] e contendo entre 21 \% e 35 \% em massa de calcário. Também foi empregada nos ensaios cal hidráulica da classe HL5, conforme a classificação da norma EN 459-1 [12]. Como requisitos químicos dessa cal estão o teor de SO3 menor ou igual a 3 \% e a cal livre superior a $3 \%$.

Para a transformação do traço de argamassa de volume para peso é necessária a determinação da massa unitária do agregado no estado solto. A norma brasileira NBR 7251 [16] estabelece as recomendações para a determinação da massa unitária do agregado no estado solto, especificando que o resultado deve ser obtido a partir da média, para três determinações. Esses resultados da massa unitária para o cimento, cal e areia são apresentados na Tabela 4. 
Tabela 4: Massa unitária do cimento, cal e areia $\left(\mathrm{em} \mathrm{kg} / \mathrm{dm}^{3}\right)$.

\begin{tabular}{|l|c|c|}
\hline cimento & cal & areia \\
\hline 1,08 & 0,50 & 1,48 \\
\hline
\end{tabular}

\subsubsection{Especificação da granulometria da areia}

A norma brasileira NBR 9778 [17] descreve os procedimentos de execução do ensaio para a determinação do índice de vazios e massa específica da argamassa no estado endurecido. As amostras utilizadas nos ensaios têm formato cúbico com a dimensão dos lados igual a $50 \mathrm{~mm}$. O índice de vazios (Iv) é a relação entre o volume de poros permeáveis e o volume total, sendo calculado pela Eq. (1).

$$
I v=\frac{M_{\text {sat }}-M_{s}}{M_{\text {sat }}-M_{i}} \times 100
$$

Onde $M_{\text {sat }}$ é a massa da amostra saturada, $M_{s}$ é a massa da amostra seca em estufa e $M_{i}$ é a massa da amostra saturada e imersa em água. A Eq. (1) define no numerador a diferença entre as massas saturada e seca, isto é, a massa de água absorvida pelo material que preenche os vazios internos comunicáveis. O denominador é descrito pela diferença entre as massas saturada e imersa, ou seja, é a massa em água que o material ocupa. Esse ensaio permite avaliar a permeabilidade à água da argamassa. A massa específica da amostra seca ( $\mu$ s) é definida pela Eq. (2). A Tabela 5 apresenta os resultados individuais dos índices de vazios e das massas específicas das argamassas.

$$
\mu s=\frac{M_{s}}{M_{s a t}-M_{i}}
$$

Tabela 5: Resultados dos cálculos do índice de vazios e massa específica de argamassas.

\begin{tabular}{c|c|c|c|c|c|c|c}
\hline Traço & $\begin{array}{c}\text { Relação } \\
\text { água/cimento }\end{array}$ & $M_{\text {sat }}$ & $M_{s}$ & $M_{i}$ & $I v$ & $\begin{array}{c}\mu \mathrm{s} \\
\left(\mathrm{g} / \mathrm{cm}^{3}\right)\end{array}$ & $\begin{array}{c}\text { Absorção } \\
\text { de água } \\
24 \text { horas }\end{array}$ \\
\hline $1: 0,25: 3$ & 0,85 & 1580,9 & 1414,7 & 815,3 & $21,71 \%$ & 1,85 & $11,75 \%$ \\
$1: 0,5: 4,5$ & 1,30 & 1552,8 & 1384,8 & 781,6 & $21,78 \%$ & 1,80 & $12,13 \%$ \\
$1: 1: 6$ & 1,72 & 1546,0 & 1367,9 & 777,6 & $23,18 \%$ & 1,78 & $13,02 \%$ \\
\hline
\end{tabular}

As massas das argamassas saturadas, secas e imersas em água foram obtidas pela média de seis amostras de geometria cúbica. Nos resultados é possível observar que o índice de vazios encontrado foi próximo de $20 \%$. Assim, pode-se concluir que os vazios permeáveis internos são significativos e dependentes da relação água/cimento. Os resultados demonstraram que a massa específica da amostra seca diminuiu de valor em função do aumento da relação água/cimento. Além disso, a absorção de água em 24 horas aumentou com o incremento da relação água/cimento. De acordo com os resultados experimentais é possível verificar que não existe uma correspondência entre a absorção de água e o índice de vazios. A Figura 2 apresenta o gráfico com dois eixos verticais de correspondência entre a absorção de água 24 horas e o índice de vazios, em função da relação água/cimento. Nota-se que à medida que aumenta a relação água/cimento ocorre também um aumento nos valores de absorção de água e índice de vazios internos da argamassa. Os ensaios de absorção de água e índice de vazios foram realizados aos 28 dias de idade da argamassa.

\subsubsection{Critérios para a Especificação dos Traços de Argamassas}

As especificações dos traços de argamassas são definidas pelas recomendações normativas ASTM C-270 [9] e BS-5628 []]. As exigências estabelecidas por estas normalizações são a consistência e a retenção de água, para as argamassas no estado fresco. Estas características não consideram o tipo de unidade (cerâmico ou concreto) e a forma de assentamento. Na Tabela 6 são apresentados os valores das propriedades da argamassa no estado fresco. Cabe salientar que este valor estabelecido de consistência (230 $\pm 10 \mathrm{~mm})$ é impraticável para assentamentos da alvenaria de blocos de concreto, ou seja, não se consegue um completo espalhamento e ajuste vertical da junta de assentamento. 




Figura 2: Relação entre a absorção de água (24h), o índice de vazios e a relação água/cimento.

Tabela 6: Exigências estabelecidas para as argamassas de assentamento.

\begin{tabular}{c|c}
\hline Propriedade & Argamassa \\
\hline Consistência (abatimento) & $230 \pm 10 \mathrm{~mm}$ \\
Retenção de água & $>75 \%$ \\
\hline
\end{tabular}

A norma ASTM C-270 [9] especifica os traços de argamassas a partir da proporção em volume de materiais, Tabela 7. As exigências estabelecidas para as propriedades mecânicas das argamassas de assentamento devem satisfazer os requisitos apresentados na Tabela 8.

Tabela 7: Especificação dos traços de argamassas, conforme a ASTM C-270 []].

\begin{tabular}{c|c|c|c}
\hline Tipo & $\begin{array}{c}\text { Cim. Portland ou } \\
\text { cimento com adição }\end{array}$ & $\begin{array}{c}\text { Cal hidráulica ou } \\
\text { leite de cal }\end{array}$ & $\begin{array}{c}\text { Proporção } \\
\text { de agregado }\end{array}$ \\
\hline M & 1 & 0,25 & Maior que 2,25 e \\
S & 1 & 0,25 a 0,50 & menor que 3 vezes \\
N & 1 & 0,50 a 1,25 & a soma dos volumes de aglomerantes \\
O & 1 & 1,25 a 2,25 & \\
\hline
\end{tabular}

Tabela 8: Propriedade mecânica da argamassa, conforme a ASTM C-270 [9].

\begin{tabular}{c|c|c|c}
\hline Tipo & $\begin{array}{c}\text { Resistência média à } \\
\text { compressão aos 28 dias (MPa) }\end{array}$ & $\begin{array}{c}\text { Ar na mistura } \\
\text { (\%) }\end{array}$ \\
\hline M & 17,2 & $>75$ & 12 \\
S & 12,4 & $>75$ & 12 \\
N & 5,2 & $>75$ & $14^{*}$ \\
O & 2,4 & $>75$ & $14 *$ \\
\hline
\end{tabular}

* Quando houver armadura incorporada à junta de argamassa, a quantidade de ar incorporado não poderá ser superior a $12 \%$.

As recomendações especificadas pela BS-5628 [ㅁ] para os traços de argamassas e limites de resistência à compressão estão apresentadas nas Tabelas 9 e 10, respectivamente. 
Tabela 9: Especificação dos traços de argamassas em volume (BS-5628 [ㅁ]).

\begin{tabular}{c|c|c|c}
\hline \multirow{2}{*}{$\begin{array}{c}\text { Designação da } \\
\text { Argamassa }\end{array}$} & \multicolumn{3}{|c}{ Tipo de argamassa } \\
\cline { 2 - 4 } (I) & $1: 0$ a $0,25: 3$ & - & - \\
(II) & $1: 0,5: 4$ a 4,5 & $1: 2,5$ a 3,5 & $1: 3$ a 4 \\
(III) & $1: 1: 5$ a 6 & $1: 4$ a 5 & $1: 5$ a 6 \\
(IV) & $1: 2: 8$ a 9 & $1: 5,5$ a 6,5 & $1: 7$ a 8 \\
\hline
\end{tabular}

Tabela 10: Propriedades mecânicas das argamassas (BS-5628 []]).

\begin{tabular}{c|c|c}
\hline \multicolumn{3}{c}{ Resistência à compressão média aos 28 dias (MPa) } \\
\hline Designação da argamassa & Testes laboratoriais & Testes em situ \\
\hline (I) & 16,0 & 11,0 \\
(II) & 6,5 & 4,5 \\
(III) & 3,6 & 2,5 \\
(IV) & 1,5 & 1,0 \\
\hline
\end{tabular}

Comparando os resultados de resistência à compressão apresentados pela ASTM C-270 [9] e BS5628 [8] , nota-se uma significativa diferença de valor para os traços "S", "N" e "O" em relação aos traços "II", "III" e "IV", respectivamente. No trabalho experimental os traços de argamassas foram mantidos constantes e definidos a partir dos requisitos e exigências das normas ASTM C-270 [ㅁ] e BS-5628 [8]]. A proporção entre aglomerante e agregado foi de 1:3. As relações água/cimento das misturas foram escolhidas em função da trabalhabilidade da mistura, de modo a proporcionar suficiente manuseio e espalhamento sob a superfície do bloco. Os traços estudados são apresentados na Tabela 11.

Tabela 11: Especificação dos traços de argamassas e proporção entre materiais.

\begin{tabular}{c|c|c}
\hline \multirow{2}{*}{ Traço } & Proporção em volume & Relação \\
\cline { 2 - 3 } & cim:cal:areia & aglomerante:agregado \\
\hline I & $1: 0,25: 3$ & $1: 2,4$ \\
II & $1: 0,5: 4,5$ & $1: 3$ \\
III & $1: 1: 6$ & $1: 3$ \\
\hline
\end{tabular}

\section{ANÁLISE DOS RESULTADOS MECÂNICOS DAS ARGAMASSAS}

Por intermédio da análise dos resultados mecânicos dos diferentes traços de argamassas é possível avaliar o comportamento do material quando submetidos a solicitações nos ensaios de compressão axial e flexão a três pontos.

\subsection{Efeitos da variação da relação a/c nas resistências mecânicas das argamassas}

A resistência à compressão das argamassas é um dos principais parâmetros comparativos de qualificação das composições estabelecidas pela ASTM C-270 [ㅁ] e BS-5628 [ㅁ] . Os ensaios de compressão foram realizados com velocidade constante de $0,002 \mathrm{~mm} / \mathrm{s}$. Os ensaios de flexão em três pontos foram realizados com velocidade de carregamento de $0,001 \mathrm{~mm} / \mathrm{s}$, em amostras prismáticas cujas dimensões: largura, altura e comprimento são 40, 40 e $160 \mathrm{~mm}$, respectivamente. A determinação das resistências foi realizada em uma prensa com controle de deslocamento, com o objetivo de se obter o comportamento póspico do material. As relações água/cimento foram fixadas de acordo com a trabalhabilidade da mistura em função do tipo assentamento da alvenaria, da necessidade do operário e de maneira que a junta permanecesse sempre com altura constante. Inicialmente a argamassa era distribuída sob o bloco de maneira a apresentar uma altura de $15 \mathrm{~mm}$, para que os blocos superiores das fiadas fossem posicionados com um martelo de borracha e nível. A altura final da junta de assentamento variou de 10 a $12 \mathrm{~mm}$. Portanto, os parâmetros de referências para a trabalhabilidade foram determinados pelo assentador. A Figura 3 apresenta a média dos 
resultados dos ensaios de compressão (amostras cúbicas e cilíndricas) e flexão. As equações para as curvas correspondentes (Figura 3) são encontradas na Tabela 12.

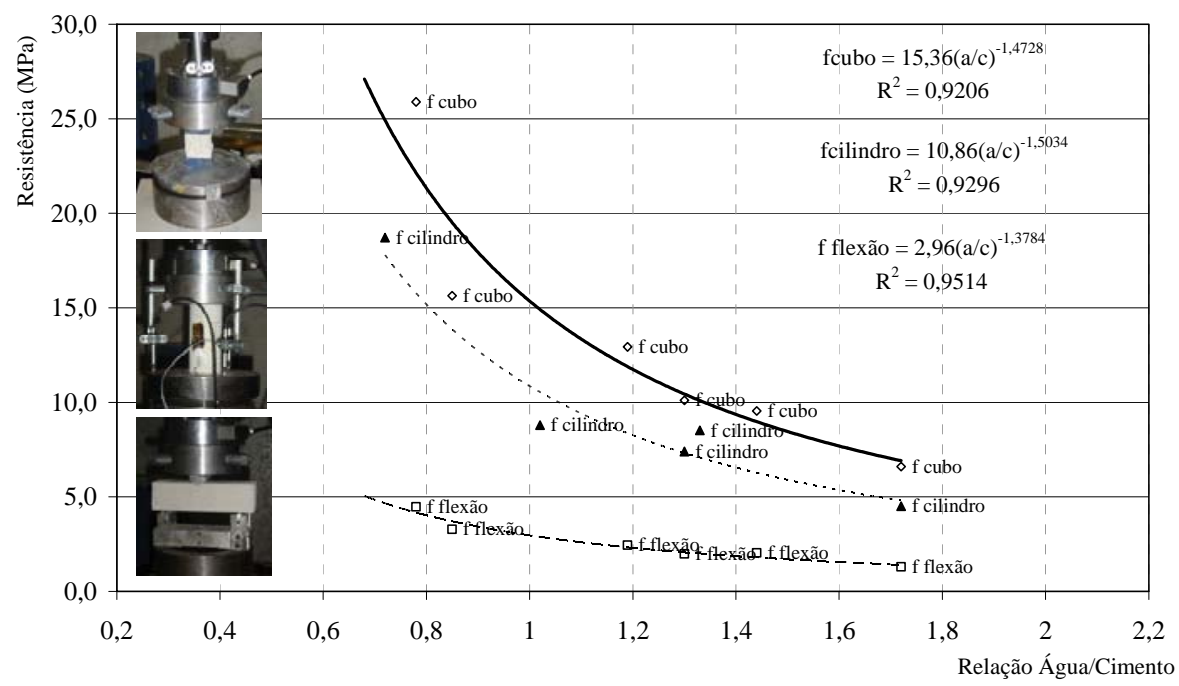

Figura 3: Resistência em função da relação água/cimento.

Tabela 12: Equações para a variação da resistência em função da relação água/cimento.

\begin{tabular}{|c|c|c|c|}
\hline & \multicolumn{3}{|c|}{ Geometria da amostra } \\
\cline { 2 - 4 } & Cúbica & Cilíndrica & Prismática \\
\hline Equação & $f_{\text {cubo }}=15,36(a / c)^{-1,4728}$ & $f_{\text {cilindro }}=10,86(a / c)^{-1,5034}$ & $f_{\text {flexão }}=2,96(a / c)^{-1,3787}$ \\
\hline
\end{tabular}

A Figura 4 apresenta os resultados entre as resistências médias dos cubos e cilindros, obtidos no ensaio de compressão, em relação à resistência a flexão da barra prismática, juntamente com as respectivas correlações. Como pode ser visto na referida figura, a função exponencial foi a que melhor representou os pontos.

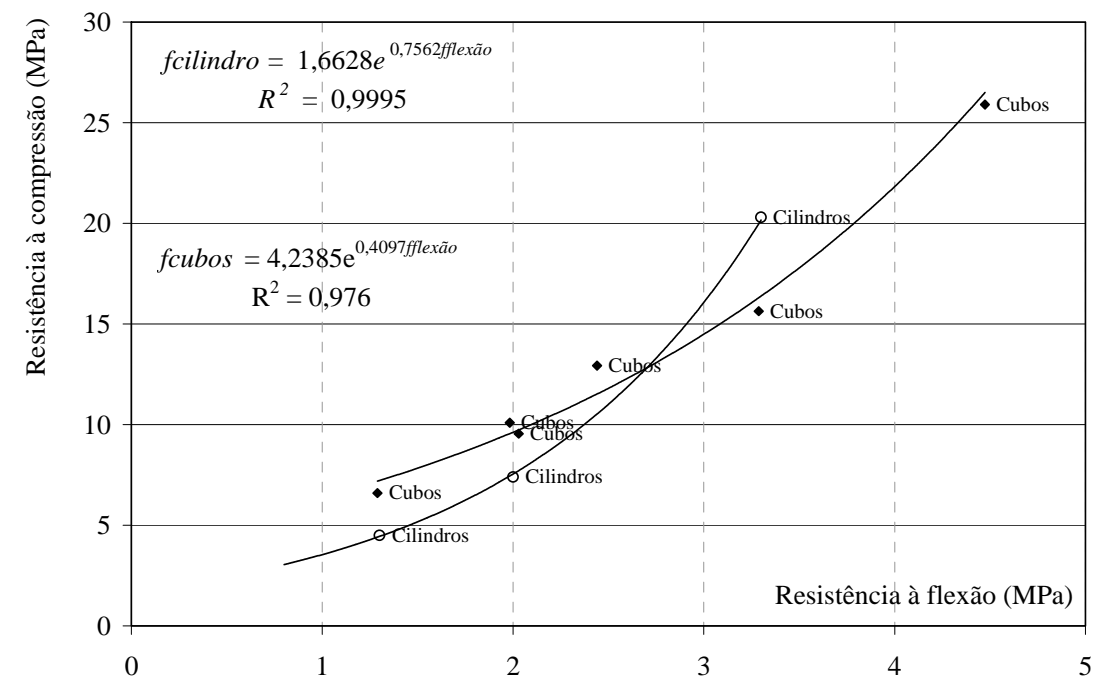

Figura 4: Resistência à compressão de amostras cúbicas e cilíndricas em função da flexão.

As equações que relacionam a resistência dos corpos-de-prova de geometria cúbica e cilíndrica à compressão, em função da resistência a flexão das amostras prismáticas estão apresentadas na Tabela 13. 
Tabela 13: Variação entre as resistências à compressão das amostras cúbicas e cilíndricas em função da resistência à flexão das amostras prismáticas.

\begin{tabular}{|l|c|c|}
\hline \multirow{2}{*}{} & \multicolumn{2}{|c|}{ Geometria da amostra } \\
\cline { 2 - 3 } & Cúbica & Cilíndrica \\
\hline Equação- Flexão (Prismática) & $f_{\text {cubo }}=4,24 . e^{0,4097 f_{\text {flexão }}}$ & $f_{\text {cubo }}=1,66 . e^{0,7562 f_{\text {flexão }}}$ \\
\hline
\end{tabular}

A Figura 5 relaciona as resistências das argamassas obtidas experimentalmente, em comparação com as propostas pelas normas BS-5628 [8] e ASTM C-270 [9]].

\subsection{Resultados do módulo de elasticidade das argamassas}

Outro parâmetro de caracterização das argamassas é o módulo de elasticidade. Esta variável serve de base para alimentar o comportamento mecânico do material quando, por exemplo, se usa programas de elementos finitos. Partindo-se da premissa que diferentes métodos de teste podem influenciar nos resultados do módulo de elasticidade se adotou os procedimentos estabelecidos pela norma brasileira NBR 8522 [18].

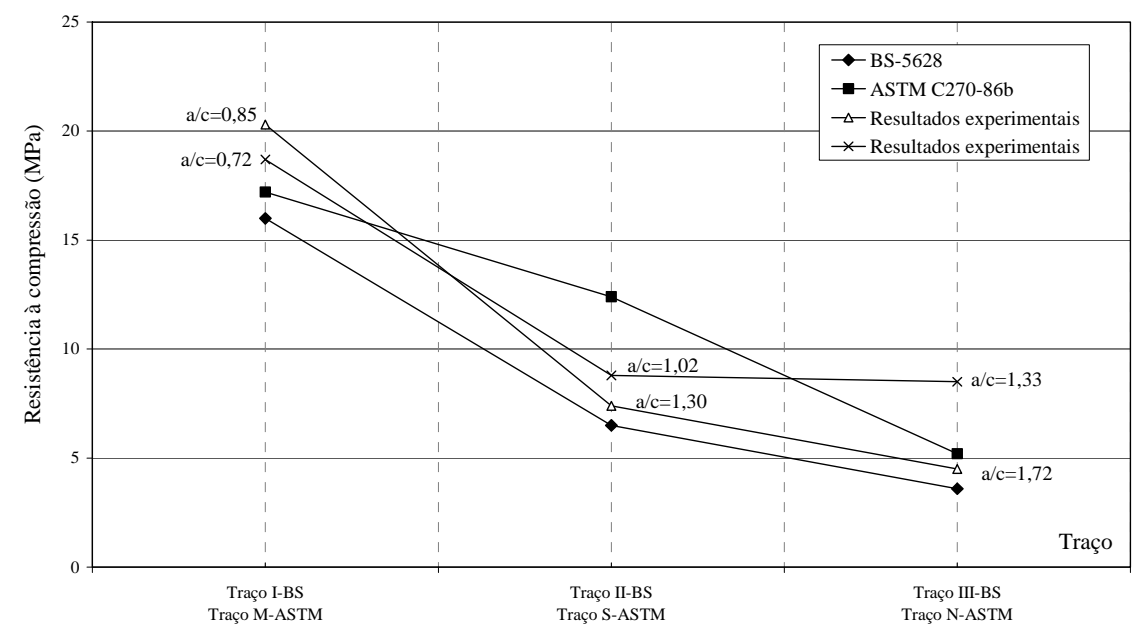

Figura 5: Relação entre a resistência da argamassa em comparação ao especificado pela BS e ASTM.

A seguir é descrito o método utilizado para a execução do ensaio. Antes de realizar o ensaio do módulo de elasticidade deve-se verificar a resistência à compressão da argamassa (fc), com o uso de duas amostras similares, cujo intuito é fixar o patamar $0,3 . f_{c}$. Para o ensaio do módulo de elasticidade, a NBR 8522 [18] estabelece uma taxa de tensão de $(0,25 \pm 0,05) \mathrm{MPa}$ /s. Durante os testes preliminares notou-se que esta velocidade não condiz com o tipo de material utilizado, ou seja, em poucos segundos a tensão na amostra atinge o valor de $0,3 . f_{c}$. Desta maneira, levando em consideração estudos anteriores de compressão em argamassas concluiu-se que uma taxa de carregamento de $0,15 \mathrm{kN} / \mathrm{s}$ é suficiente para as condições do ensaio. Na Figura 6 é mostrado o procedimento para a verificação das deformações lidas nas bases de medidas, ou seja, dez ciclos de carga e descarga (procedimento 0), quatro patamares lineares crescentes (procedimentos 1, 4, 7 e 11), quatro patamares lineares decrescentes (procedimentos 3, 6, 9 e 13) e cinco patamares constantes (2, 5, 8, 10 e 12). O módulo de elasticidade do material é obtido pelas tensões e deformações médias entre os procedimentos 12 e 10.

Antes da execução do ensaio, realizou-se o ajuste na posição da amostra, por meio dos seguintes passos: colocou-se o corpo-de-prova em posição centrada entre os pratos da prensa; aplicou-se uma força aproximada de $10 \%$ do valor previsto na ruptura; verificaram-se as deformações registradas pelos medidores, caso a diferença entre as deformações lidas nesses medidores apresentasse um valor maior que $20 \%$ da maior das deformações, fazia-se a descarga do corpo-de-prova e procedia-se ao ajuste do centro da amostra. Nos estudos iniciais foram utilizados corpos-de-prova cilíndricos de $50 \mathrm{~mm}$ de diâmetro e $100 \mathrm{~mm}$ de altura. Um extensômetro elétrico do tipo strain gauge foi colado nas amostras, a fim de se comparar as deformações verticais com os três transdutores lineares de deslocamentos (LVDT’s), distanciados de 120o. Os LVDT’s 
foram fixados na célula de carga e apoiados no prato inferior da máquina de ensaios. Assim, para o cálculo das deformações a base de medida foi a altura total do cilindro, Figura 7.



Figura 6: Procedimentos utilizados para a determinação do módulo de elasticidade das argamassas.

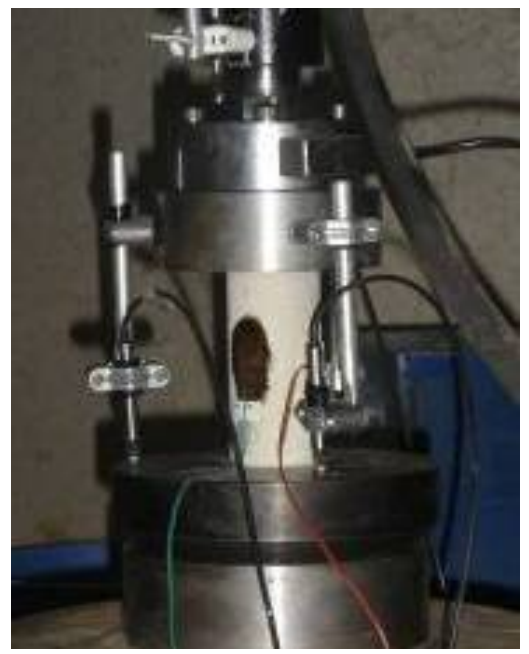

Figura 7: Determinação do módulo de elasticidade com extensômetros elétricos e LVDT’s.

O procedimento de ensaio consiste em aplicar inicialmente no corpo-de-prova uma pré-tensão de 0,1 MPa, onde os registros de deslocamentos nos LVDT’s são zerados; O teste é então iniciado, respeitando os procedimentos da Figura 6. Os resultados dos ensaios permitiram as seguintes verificações:

- A superfície superior da amostra deve estar perfeitamente retificada, a fim de garantir que não existam concentrações de tensões em pontos localizados da amostra que, por conseqüência, geram rotações e influência nos valores das deformações lidas;

- Ocorreram deformações residuais significativas nos topos das amostras, quando os LVDT’s são posicionados em toda altura do corpo-de-prova, Figura 7. A Figura 8 apresenta a curva tensão-deformação da argamassa utilizando o extensômetro elétrico e os LVDT’s (71941, 71942 e 71943);

- A resina regularizadora aplicada nas faces superior e inferior da amostra de argamassa pode afetar os resultados de deformação, se a mesma possuir rigidez superior à argamassa;

- Os extensômetros elétricos apresentaram resultados de deformações residuais praticamente insignificantes, pois foram posicionados no terço médio, eliminando o efeito nas extremidades da amostra, na interface corpo-de-prova/máquina de ensaios;

- Os módulos de elasticidade da argamassa, calculados pelo LVDT-71941, LVDT-71942 e LVDT71943, apresentaram valores significativamente diferentes. 


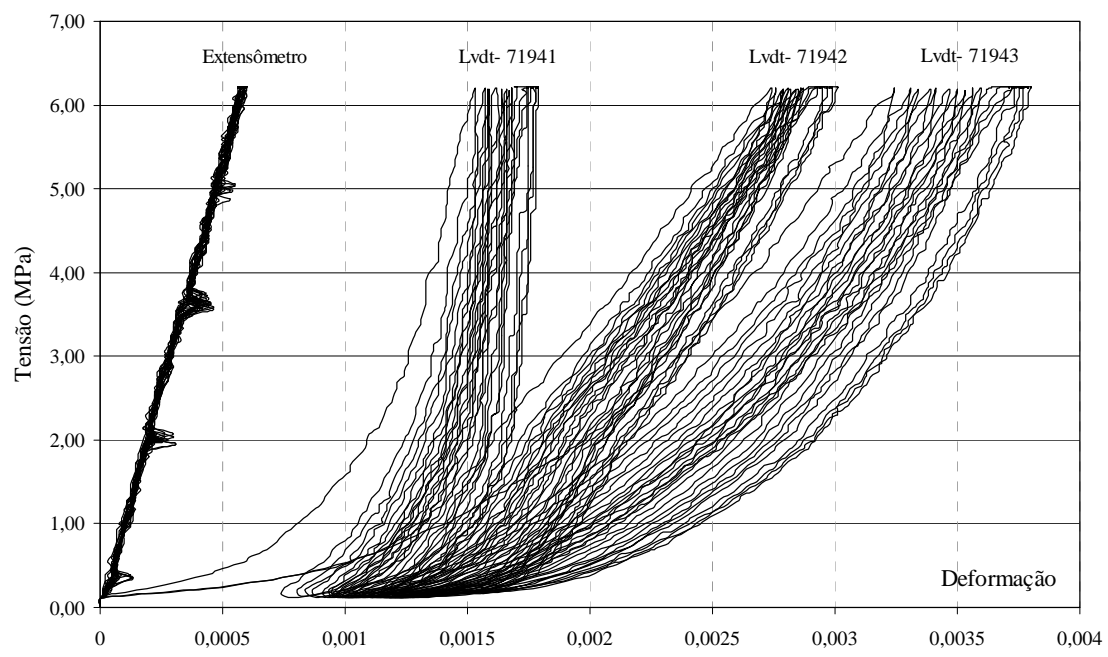

Figura 8: Relação entre tensão e deformação utilizando na amostra LVDT’s e o strain gage.

Os resultados obtidos nos ensaios possibilitaram concluir que para eliminar os efeitos das interfaces, anéis metálicos devem ser posicionados no terço médio da amostra para a fixação dos LVDT's. A base de medida das deformações foi de 27 mm, Figura 9.

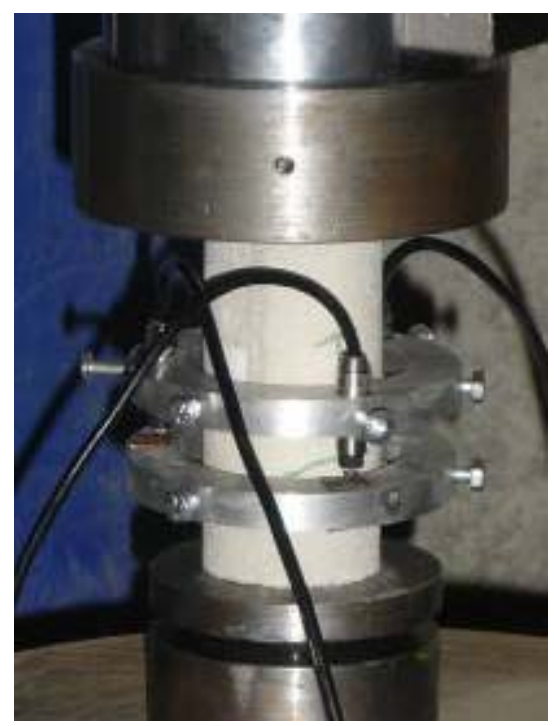

Figura 9: Esquema do ensaio para a determinação do módulo de elasticidade da argamassa.

A Figura 10 apresenta os resultados individuais entre o módulo de elasticidade secante no nível de tensão 0,3. $f_{c}$, em função da resistência à compressão, para os diferentes traços de argamassa.

A Tabela 14 mostra os valores médios de resistência à compressão e módulo de elasticidade, dos diferentes traços de argamassas, com o respectivo desvio-padrão (s.d), coeficiente de variação (c.v.) e número de amostras ensaiadas (n). Os traços foram denominados conforme a norma BS-5628 [8] e, para cada traço foram utilizadas duas relações água/cimento. 


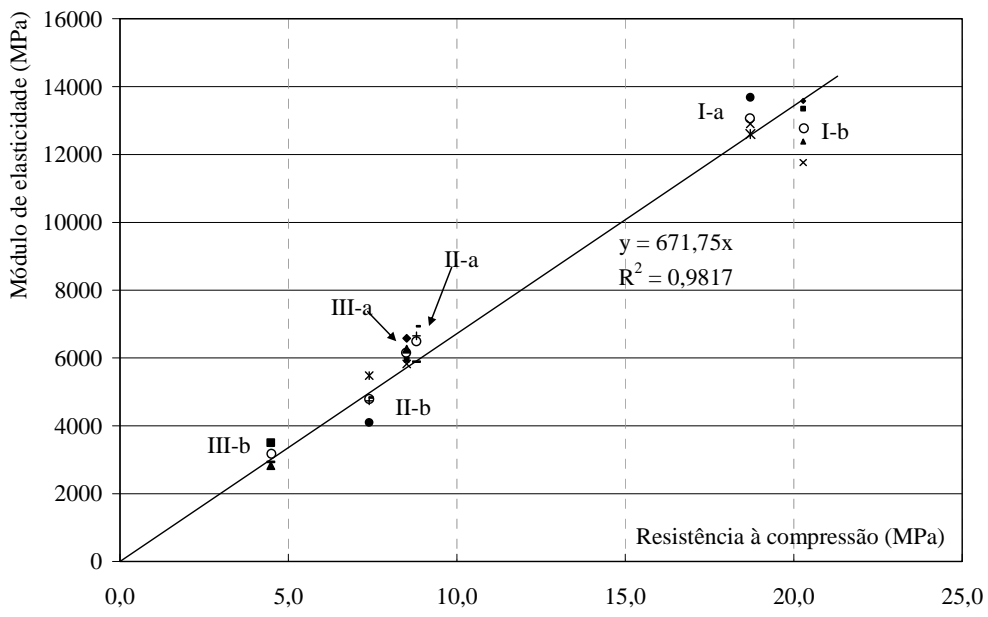

Figura 10: Módulo de elasticidade secante em relação a resistência à compressão.

Tabela 14: Valores médios da resistência a compressão e módulo de elasticidade das argamassas.

\begin{tabular}{ccccccccc}
\hline \multirow{2}{*}{ Traço } & \multicolumn{3}{c}{ Resistência à compressão } & \multicolumn{5}{c}{$\mathrm{E}_{30 \%}$} \\
\cline { 2 - 9 } & Média (MPa) & s.d (MPa) & c.v (\%) & $\mathrm{n}$ & Média (MPa) & s.d (MPa) & c.v (\%) & $\mathrm{n}$ \\
\hline I & 20,3 & 0,32 & 1,6 & 3 & 12769 & 846 & 6,6 & 4 \\
I $^{*}$ & 18,7 & 0,86 & 4,6 & 4 & 13065 & 558 & 4,3 & 3 \\
II & 7,4 & 0,77 & 10,4 & 3 & 4788 & 565 & 11,8 & 4 \\
II $^{*}$ & 8,8 & 0,13 & 1,5 & 4 & 6491 & 537 & 8,3 & 3 \\
III & 4,5 & 0,63 & 14,0 & 3 & 3177 & 343 & 10,8 & 4 \\
III $^{*}$ & 8,5 & 0,27 & 3,1 & 4 & 6152 & 339 & 5,5 & 4 \\
\hline
\end{tabular}

Pode ser observado que o coeficiente de variação do módulo de elasticidade das argamassas variou de 4,3 a 11,8 \% (ver Tabela 14). Contudo, esses valores podem ser considerados pequenos.

A Figura 11 mostra valores da resistência média à compressão e do módulo de elasticidade (considerando erro padrão de 5 \%), obtendo a faixa de variação linear passando pela origem. Os números 1, 2 e 3 (Figura 11) representam as retas de aproximação entre o módulo de elasticidade e a resistência à compressão, quando considerado o erro-padrão de $\pm 5 \%$.



Erro-padrão de 5\% no valor do módulo de elasticidade e na resistência à compressão

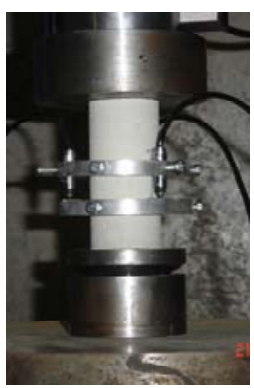

Figura 11: Faixa de variação da função linear de aproximação entre o módulo de elasticidade secante e a resistência à compressão. 
As variáveis mecânicas (resistência à compressão e módulo de elasticidade) e as variáveis físicas (relação água/cimento e massa específica da amostra seca) das argamassas encontram-se relacionadas na Figura 12.

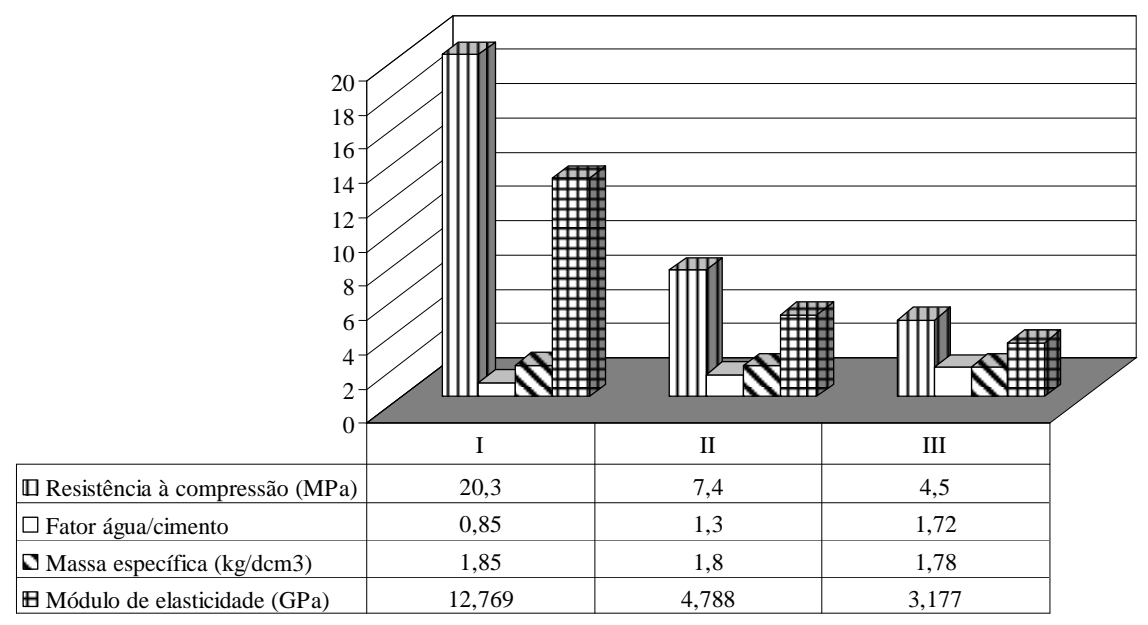

Figura 12: Resultados entre as variáveis mecânicas e físicas das argamassas.

Os ensaios de compressão nos corpos-de-prova de argamassa foram realizados com controle de deslocamento, sob velocidade constante de $0,002 \mathrm{~mm} / \mathrm{s}$. Por meio dos resultados, mostrados na Figura 13, é possível verificar que a argamassa de resistência 19,1 MPa apresentou um comportamento linear até próximo 0,3. $f_{c}$. Para valores maiores que este, começa a ocorrer deformações não-lineares. No caso das argamassas de resistência à compressão de 3,7 MPa e 7,09 $\mathrm{MPa}$ as deformações não-lineares acontecem quando as tensões atingem $0,37 . f_{c}$ e 0,43. $f_{c}$, respectivamente (ver Figura 13). A argamassa de resistência à compressão de 19,1 MPa possui um comportamento pós-pico parabólico. As argamassas de resistência à compressão de 3,7 e 7,09 MPa apresentaram um comportamento dúctil, onde após a ruptura houve um aumento progressivo das deformações mantendo-se praticamente constante o nível de tensão aplicado. A Figura 13 mostra o diagrama tensão-deformação salientando, com uma seta, o ponto onde começam as deformações não-lineares da argamassa. Também podem ser visualizados a resistência última da argamassa, $f_{c}$, a deformação máxima na ruptura e o comportamento pós-pico do material.



Figura 13: Diagrama tensão-deformação das argamassas, ensaiadas à compressão. 


\subsection{Comportamento triaxial das argamassas}

Quando submetidas a um carregamento vertical as alvenarias geram um estado de tensões que provoca, na argamassa de assentamento, tensões horizontais devidas à aderência existente entre a unidade (bloco) e a argamassa.

Poucos estudos foram realizados para determinar as mudanças no comportamento mecânico das argamassas à compressão e, por conseqüência, nos modos de ruptura das alvenarias quando submetidas a cargas verticais. As propriedades mecânicas dos materiais que compõem a alvenaria são muitas vezes tratadas como constantes e, geralmente, são obtidas a partir de ensaios uniaxiais, não representando, portanto o estado de tensões real na alvenaria. Em função disso, estudar o comportamento da argamassa é fundamental para compreender os critérios de ruptura da alvenaria (por indução de tração no bloco ou por esmagamento da junta horizontal de argamassa). Alguns critérios de ruptura se baseiam em análises do conjunto, no qual o principal parâmetro utilizado é a proporção entre os módulos de elasticidade do bloco e da argamassa. A primeira etapa no estudo do conjunto bloco-argamassa é conhecer o ganho de resistência gerado pelo confinamento da argamassa na junta e, com isso, compreender as diferenças no comportamento da resistência do material, à medida que muda o estado de tensões atuante na argamassa.

\subsubsection{Resistência à Compressão Confinada das Argamassas}

Os corpos-de-prova foram colocados dentro do cilindro de confinamento, onde se aplicou uma tensão lateral constante. Os fios soldados aos strain-gauges foram instalados pelas ranhuras das rótulas e conectados a caixa comutadora, Figura 14. O procedimento de ensaio seguiu a seguinte metodologia, de acordo com o tipo de argamassa:

- Para argamassas fortes e baixos níveis de tensões laterais: a amostra foi colocada na máquina com os instrumentos de medição e centralizada para eliminar as possíveis excentricidades. Inicialmente foi aplicada a tensão lateral de confinamento até o nível desejado, sendo então esta tensão mantida constante. Em seguida aplicou-se uma tensão básica de $\sigma \mathrm{b}=0,5 \mathrm{MPa}$ e fez-se a leitura das deformações axial e lateral. Dando continuidade ao ensaio, aumentou-se as tensões em proporções constantes de 0,6 MPa $\pm 0,4 \mathrm{MPa}$ até a tensão atingir o valor de $\sigma_{a}=\frac{1}{3} f_{c}$, da resistência à compressão do material não confinado. Manteve-se a tensão constante por 60 segundos e então se fez a leitura das deformações durante os sucessivos 30 segundos para cada linha de medida. Em seguida se reduziu a carga na mesma proporção usada para o carregamento. Repetiu-se o mesmo ciclo, no mínimo por 2 vezes adicionais, usando o mesmo nível de carregamento e descarregamento e mantendo as tensões ( $\sigma \mathrm{a}$ e $\sigma \mathrm{b}$ ) constantes por um período de 60 segundos. Completados os ciclos de medidas aumentou-se a carga aplicada na amostra até a ruptura da mesma;

- Para argamassas fortes e altos níveis de tensão lateral: o procedimento inicial foi igual ao utilizado no item anterior. Porém a tensão básica aplicada foi de $\sigma b=1,0 \mathrm{MPa}$. Aumentou-se as tensões em proporções constantes de 1,0 MPa $\pm 0,2 \mathrm{MPa}$. Os procedimentos seguintes foram os mesmos já citados;

- Para argamassas fracas e baixos níveis de tensões laterais: a tensão básica aplicada foi de $\sigma b=0,6$ MPa $\pm 0,4$ MPa. E finalmente para as argamassas fracas e altos níveis de tensões laterais, a tensão básica aplicada foi de $\sigma b=1,0 \mathrm{MPa}$. As tensões foram aumentadas em proporções constantes de 0,6 MPa \pm 0,4 MPa.

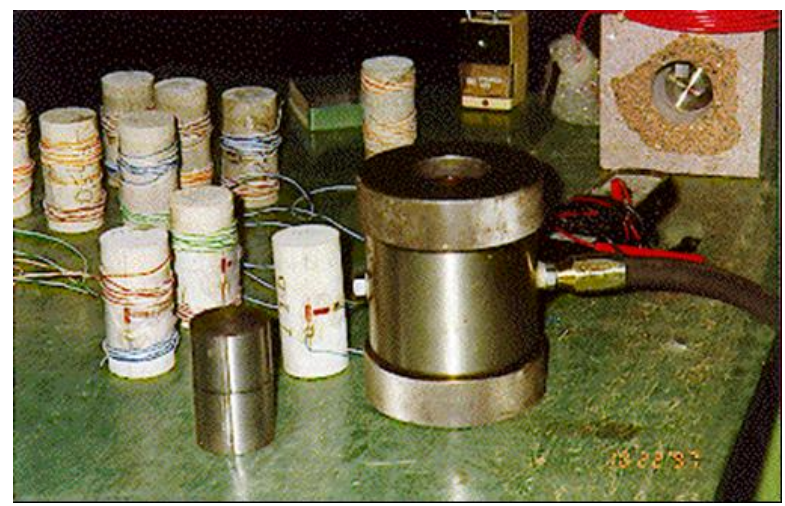

Figura 14: Câmara triaxial dimensionada para suportar tensões de confinamento de 50 MPa. 
A pesquisa de MOHAMAD [19] conduziu testes em argamassas confinadas. O trabalho procurou caracterizar as argamassas por meio de suas propriedades mecânicas. A Tabela 15 mostra os resultados obtidos para a resistência à compressão de argamassas em cilindros de $50 \mathrm{~mm}$ de diâmetro, em função da tensão de confinamento. Para o traço de argamassa 1:1:6 foram utilizadas duas relações água/cimento, citadas como “a” e "b”.

Tabela 15: Resistências à compressão das argamassas confinadas.

\begin{tabular}{ccccc}
\hline $\mathrm{f}_{\text {tm }}$ & \multicolumn{4}{c}{ Traço } \\
\cline { 2 - 5 }$(\mathrm{MPa})$ & $1: 0,25: 3$ & $1: 0,5: 4,5$ & $1: 1: 6^{(\mathrm{a})}$ & $1: 1: 6^{(\mathrm{b})}$ \\
\hline 0 & 34,6 & 24,1 & 11,4 & 5,1 \\
0,5 & 36,7 & 19,4 & 13,7 & 6,6 \\
1 & 39,7 & 25,7 & 14,3 & 7,6 \\
2,5 & 44,6 & 31,0 & 17,8 & - \\
4 & - & - & 22,4 & - \\
\hline
\end{tabular}

A Figura 15 ilustra a variação da resistência à compressão da argamassa em função das tensões de confinamento. A envoltória mostrou-se linear, com elevados valores para o coeficiente de correlação (R2).

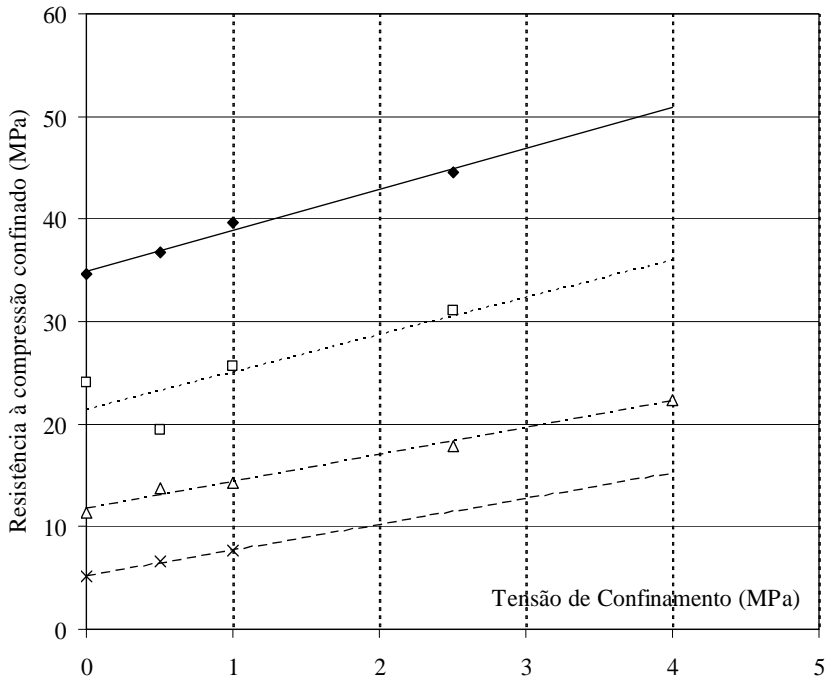

$$
\begin{aligned}
& \text { - Traço 1:0,25:3 } \\
& \text { - Traço 1:0,5:4,5 } \\
& \triangle \text { Traço 1:1:6 } \\
& \times \text { Traço 1:1:6 } \\
& \text { _ Linear (Traço 1:0,25:3) } \\
& \text {...... Linear (Traço 1:0,5:4,5) } \\
& \text {-. - . Linear (Traço 1:1:6) } \\
& \text { - - - - Linear (Traço 1:1:6) } \\
& \mathrm{y}=3,9857 \mathrm{x}+34,914 \\
& \mathrm{R}^{2}=0,9848 \\
& \mathrm{y}=3,6286 \mathrm{x}+21,421 \\
& \mathrm{R}^{2}=0,6713 \\
& y=2,6065 x+11,75 \\
& \mathrm{R}^{2}=0,989 \\
& y=2,5 x+5,1833 \\
& \mathrm{R}^{2}=0,9868
\end{aligned}
$$

\begin{tabular}{|c|c|}
\hline $\begin{array}{l}\text { Argamassa } \\
\text { Tipo de traço }\end{array}$ & Equação \\
\hline $1: 0,25: 3$ & $f_{\text {arg }}{ }^{*}=f_{\text {arg }}+4,0 \cdot f_{\text {tm }}$ \\
\hline $1: 0,5: 4,5$ & $f_{\text {arg }}{ }^{*}=f_{\text {arg }}+3,6 \cdot f_{\text {tm }}$ \\
\hline $1: 1: 6^{(a)}$ & $f_{\text {arg }}{ }^{*}=f_{\text {arg }}+2,6 \cdot f_{t m}$ \\
\hline $1: 1: 6^{(b)}$ & $f_{\text {arg }}{ }^{*}=f_{\text {arg }}+2,5 \cdot f_{t m}$ \\
\hline
\end{tabular}

Figura 15: Envoltória de ruptura da argamassa confinada.

A Tabela 16 apresenta as equações que descrevem a relação entre a resistência à compressão das argamassas, conforme aumenta a tensão lateral confinante.

Tabela 16: Equações que descrevem as rupturas das argamassas confinadas.

Os dados mostram que com o aumento da tensão confinante, há um incremento na resistência da argamassa. A envoltória de ruptura da argamassa comprimida triaxialmente aproximou-se da envoltória de ruptura de Mohr-Coulomb e apresentou um comportamento linear. Os coeficientes angulares dos traços de 
argamassas (1:1:6) com diferentes relações água/cimento apresentaram valores muito próximos. Este resultado pode indicar que argamassas com resistências menores que $10 \mathrm{MPa}$ possuem comportamentos similares, para o aumento de resistência confinada. MOHAMAD [19] determinou, a partir do critério de ruptura de Mohr-Coulomb, a reta tangente aos círculos de Mohr e os valores da coesão e do ângulo de atrito interno do material, como mostram os gráficos da Figura 16.

\subsubsection{Módulo de Elasticidade e Coeficiente de Poisson das Argamassas}

KHOO [20] determinou por meio de ensaios experimentais o módulo de elasticidade e o coeficiente de Poisson confinado das argamassas. De acordo com os resultados obtidos pelo autor, o módulo de elasticidade do traço de argamassa 1:1:6, apresentou uma tendência para diminuir de valor com o aumento da tensão confinante. Já para o traço 1:0,25:3 não houve uma diferença significativa no valor do módulo de elasticidade com as tensões de confinamento. O coeficiente de Poisson diminuiu de valor com o aumento da tensão confinante, para os dois traços de argamassa (1:0,25:3 e 1:1:6). Essa diminuição foi linear para o traço 1:0,25:3 e exponencial para o traço de argamassa 1:1:6. O valor do coeficiente de Poisson para o traço 1:1:6 foi de aproximadamente 0,05, para uma tensão lateral de $4 \mathrm{MPa}$.

ATKINSON et al. [21] analisaram o diagrama tensão-deformação axial e lateral das argamassas confinadas triaxialmente para diferentes níveis de tensões confinantes. A conclusão obtida nos testes evidenciou a transição de um comportamento frágil, em baixos níveis de tensões, para um comportamento dúctil para altas tensões. As argamassas confinadas apresentaram um comportamento não-linear para níveis de carregamento aproximadamente superiores a $50 \%$ da carga última. Os autores classificaram esse comportamento como: frágil, dúctil e bilinear.
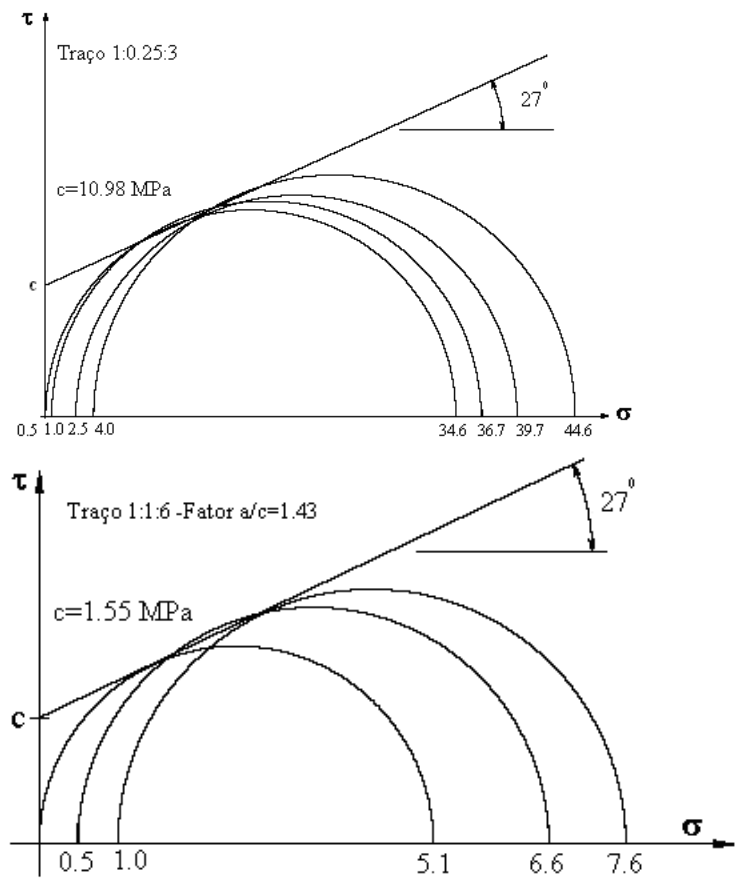


Figura 16: Determinação do ângulo de atrito das argamassas confinadas triaxialmente.

O caráter frágil é designado pela ruptura abrupta, ou seja, o material perde a capacidade resistente sem aviso. O caráter dúctil é caracterizado pelo aumento das deformações, para um mesmo nível de tensão axial. O caráter bilinear é caracterizado pelo contínuo aumento das tensões pós-ruptura. O diagrama tensãodeformação da argamassa de traço 1:0,5:4,5 mostrou um comportamento frágil, para níveis de tensões laterais (0,2, 0,7 e 1,7 MPa). Nas demais tensões laterais (3,45, 6,9 e 10,9 MPa) mostrou ter características dúcteis. O traço 1:1:6 apresentou caráter frágil para níveis de tensões de 0,2 e 0,7 MPa mas, para o nível de tensão de 1,7 MPa, apresentou um caráter dúctil. Nas demais tensões confinantes (3,45, 6,9 e 10,9 MPa) apresentou um caráter bilinear.

A Figura 17 apresenta os resultados experimentais da variação do módulo de elasticidade com o aumento das tensões de confinamento. No gráfico verifica-se um aumento do módulo de elasticidade em função da tensão confinante, para o traço de argamassa 1:0,25:3 e 1:0,5:4,5 e, uma diminuição no módulo de elasticidade para os traços 1:1:6. Da mesma forma KHOO [20] obteve uma diminuição no módulo de 
elasticidade tangente inicial para o traço 1:1:6. Estudos para a verificação dos vazios internos, perda de coesão material entre agregado e aglomerante devem ser estabelecidos para avaliar o motivo da diminuição do módulo de elasticidade para os traços mais fracos.



Figura 17: Módulo de elasticidade das argamassas em função das tensões de confinamento.

Em paralelo aos ensaios para a determinação do módulo de elasticidade, foi obtido o valor do coeficiente de Poisson confinado das argamassas para os níveis de tensões iniciais (30\% da resistência à compressão) e próximos da ruptura. Verificou-se uma significativa redução no coeficiente de Poisson das argamassas com o aumento das tensões laterais confinantes.

\subsubsection{Modelo Comportamental da Variação do Coeficiente de Poisson em Função do Aumento da Tensão Confinante}

O principal objetivo deste item é descrever o comportamento do coeficiente de Poisson das argamassas sob compressão triaxial. As atuais especificações para o coeficiente de Poisson definem usualmente valores constantes ao longo de um ciclo de carregamento, não retratando as mudanças ocorridas devido ao confinamento da argamassa. A teoria apresentada procura descrever o comportamento não-linear das argamassas juntamente com o modo de ruptura comumente verificado nos ensaios experimentais.

HAYEN et al. [22] submeteram argamassas constituídas por areia e cal, com resistência à compressão uniaxial de 1,85 MPa, à ensaios triaxiais, onde a tensão confinante aplicada era função da proporção das tensões horizontais (laterais), em relação à tensão vertical aplicada denominada de k. As proporções utilizadas mantiveram-se constantes ao longo dos testes, cujos valores foram 0, 0,15 e 1,0. A análise obtida do comportamento material, para um estado de tensões multiaxial permitiu as seguintes conclusões: as análises das deformações volumétricas, sob carregamento triaxial, evidenciaram para $\mathrm{k}<0,25$ a existência de um mecanismo de ruptura por cisalhamento. Inicialmente, ocorreu uma diminuição no volume da amostra, provavelmente gerada pelo fechamento das fissuras e defeitos internos na argamassa, passando por um posterior aumento de volume. Surge, portanto uma rede de micro-fissuras que se propagam desenvolvendo as chamadas bandas de cisalhamento; quando a proporção utilizada foi $\mathrm{k} \geq 0,25$ a ruptura da argamassa não coincidiu com um aumento do volume; ao contrário, foram verificadas reduções constantes de volume e evidências que indicavam rupturas características de poro-colapso. O mecanismo de poro-colapso em argamassas foi identificado por meio da medição do volume total de poros por submersão em vácuo. A análise da estrutura porosa foi realizada por intrusão de mercúrio e via microscópio eletrônico de varredura. Análises anteriores mostraram algumas alterações da estrutura interna da argamassa, sob condições triaxiais, para uma proporção $\sigma \mathrm{h} / \sigma \mathrm{v}$ acima de 0,5 . Os autores destacam uma diminuição na porosidade total para proporções $\sigma \mathrm{h} / \sigma \mathrm{v}$ acima de 0,5 .

Com o objetivo de avaliar as fissuras e a porosidade das argamassas, foram cortados com o auxílio de um disco de corte, corpos-de-prova retangulares para visualização no microscópio eletrônico de varredura. Em seguida essas amostras foram partidas em duas metades. A Figura 18 mostra as imagens para o traço de argamassa denominado como I-b, ampliado 40x (a), 200x (b), 500x (c), com as respectivas escalas. Como pode ser visto (Figura 18 (a)) tem-se uma superfície lisa, gerada pela expulsão do agregado devido à quebra 
da amostra em duas metades. Também se pode visualizar, na área demarcada, uma distribuição de poros aleatórios, sem interelação. Ampliando agora a imagem (Figura 18 (b)) na região dos poros, pode ser visto o contorno do grão de areia arrancado e os vazios nesta interface. Nota-se a existência de outros poros menores na superfície entre o agregado e a pasta de cimento, trincas em torno desses poros conectando-os e criando uma rede de capilares. Essas trincas sugerem que as mesmas são por retração na secagem entre a zona de transição do agregado com a pasta de cimento. Na Figura 18 (c) pode-se visualizar o interior do poro, onde aparecem fissuras de diferentes tamanhos e conectadas entre si.

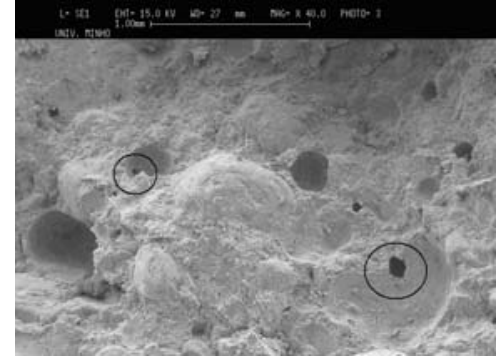

(a)



(b)



(c)

Figura 18: Imagens da argamassa de traço I-b com diferentes magnitudes de ampliação.

OTTOSEN [23] propôs um modelo constitutivo para concretos de alta resistência baseado na elasticidade não-linear, sendo este adotado pelo CEB (Comitê Euro-International du Béton), para ser incluído no CEB Model Code 1990. O modelo proposto por Ottosen consiste em estabelecer patamares de variação do coeficiente de Poisson em função do aumento do índice de não-linearidade $\beta$, que fornece a proporção entre a tensão aplicada em relação a resistência última. Quando este atinge o valor $\beta 1$ dá-se início a um aumento significativo no valor do coeficiente de Poisson. Esse modelo apresenta um coeficiente de Poisson uniaxial constante ( $v$ ia), até o nível de tensão em relação à resistência última $(\beta 1)$ ser igual 0,8 . A partir deste ponto ocorre um aumento significativo no valor do coeficiente de Poisson, até $\beta$ ser igual a 1 onde atinge o máximo valor para o coeficiente de Poisson (vfa).

A Figura 19 apresenta a variação do coeficiente de Poisson, em função de $\beta$, proposta por OTTOSEN [23] para concretos de alta resistência. É sabido que quando se trabalha com concretos de alta resistência (60 a $120 \mathrm{MPa}$ ), o aumento da tensão lateral não influencia, significativamente, o valor do coeficiente de Poisson até próximo da ruptura. Este fato ocorre devido ao fato da proporção máxima aplicada na tensão lateral, em relação à resistência última do corpo-de-prova, chegar apenas a 10 a 20 \%, no máximo, da resistência última do mesmo. As argamassas, ao contrário do concreto, possuem um nível de resistência entre 2 a $10 \mathrm{MPa}$. Para estes casos o aumento nas tensões laterais confinantes é significativo em relação à resistência última da argamassa, pois chegam a atingir proporções entre 50 a 100 \% da resistência última da amostra.



Figura 19: Variação do comportamento do Poisson, proposto por OTTOSEN [23].

As Eqs. (3) e (4) representam o comportamento do coeficiente de Poisson no modelo de OTTOSEN [23]. 


$$
\begin{aligned}
& v_{a}=v_{i}^{a} ; \text { se, } \beta \leq \beta_{1}, \\
& v^{a}=v_{f}^{a}-\left(v_{f}^{a}-v_{i}^{a}\right) \cdot \sqrt{1-\left(\frac{\beta-\beta_{1}}{1-\beta_{1}}\right)} ; \text { se, } \beta>\beta_{1}
\end{aligned}
$$

Entretanto, os resultados nos ensaios realizados por KHOO [20], ATKINSON et al. [21], MOHAMAD [19] e HAYEN et al. [22], indicaram uma modificação gradativa do coeficiente de Poisson com o aumento da tensão lateral confinante, ou seja, o modelo de OTTOSEN [23] não reproduz um estado triaxial de tensões verdadeiro para as argamassas. Assim, uma proposta generalizada para o coeficiente de Poisson da argamassa, ao longo de um carregamento pode ser visualizada na Figura 20. Para o caso a, o comportamento do Poisson diminui até atingir $\beta 1$; após esta fase ocorre um aumento gradativo do coeficiente de Poisson. Para o caso b, o comportamento do Poisson diminui até atingir $\beta 1$ quando, repentinamente, ocorre o aumento do Poisson devido ao poro-colapso e a conseqüente perda de coesão da argamassa. A Figura 20 mostra em detalhe o comportamento do coeficiente de Poisson através do modelo hipotético que descreve o início da ruptura da argamassa confinada. As linhas tracejadas são as hipóteses de comportamento do coeficiente de Poisson, a partir da modificação do modelo de OTTOSEN [23]].

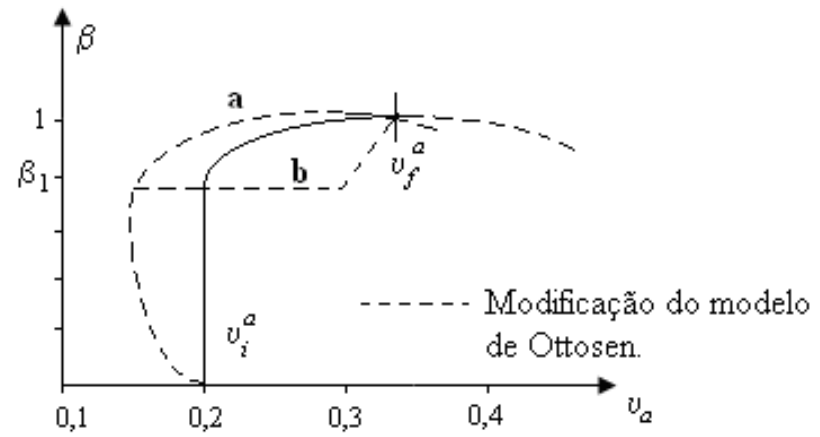

Figura 20: Generalização da proposta de OTTOSEN [23] para argamassas confinadas.

As Equações (5) e (6) representam o comportamento do coeficiente de Poisson das argamassas com o aumento das tensões laterais conseguindo, desta forma, representar a modificação do modelo de OTTOSEN [23]. Assim, quando $\beta$ atingir um valor específico, designado por $\beta 1$, haverá uma perda de coesão numa das interfaces e, por conseqüência, um aumento do coeficiente de Poisson.

$$
\begin{aligned}
& v^{a}=\left(v_{i}^{a}\right) \cdot e^{-\beta} ; \text { se, } \beta \leq \beta_{1} \\
& v^{a}=\left(v_{i}^{a}\right) \cdot e^{\beta} ; \text { se, } \beta>\beta_{1}
\end{aligned}
$$

\section{CONCLUSÕES}

As principais conclusões deste trabalho podem ser assim apresentadas:

- Os traços de argamassas especificados pela BS 5628 [8] e ASTM C-270 [9] e os resultados experimentais são dependentes da relação água/cimento. As normas não sugerem parâmetros de trabalhabilidade em função do tipo de assentamento. Isso interfere nos resultados mecânicos, causando inconsistências entre os resultados mecânicos obtidos experimentalmente e os fornecidos pelas normalizações;

- Não existe uma relação entre o teor de ar na mistura (\%) de acordo com a ASTM C-270 [9] e o índice de vazios (NBR 9778 [17]). Notou-se que o índice de vazios foi maior que o esperado. Isso pode justificar o modo de ruptura das argamassas de traço II e III ser dúctil e, principalmente, a ocorrência do prolongamento da deformação pós-ruptura; 
- Existe uma relação potencial entre as resistências das amostras de geometrias cúbicas, cilíndricas (compressão) e prismáticas (flexão) em função da relação água/cimento das argamassas. Também, se verificou um paralelismo entre a resistência à compressão do cubo e cilindro em função da relação água/cimento. A proporção média entre a resistência da amostra cilíndrica em função da cúbica é de 0,70 ;

- A relação entre as resistências das amostras cúbicas e cilíndricas em função da resistência da amostra prismática à flexão foi uma equação exponencial. Para as amostras cúbicas ou cilíndricas, a proporção entre a resistência à compressão e flexão foi de 0,19 ;

- Para o ensaio do módulo de elasticidade das argamassas, os LVDT's devem ser posicionados no terço médio da amostra. Caso contrário as imperfeições no topo e base podem afetar os resultados de deslocamento. Também quanto à adoção de extensômetros se deve ter o cuidado com o tipo de resina regularizadora, pois poderá ter rigidez superior ao material testado;

- Existe uma tendência do valor do coeficiente de Poisson diminuir em função da resistência da argamassa. Os traços do tipo II e III apresentaram valores de 0,10 e 0,06, respectivamente. O coeficiente de Poisson do traço designado por I foi de 0,16 ;

- A função linear é a que melhor ajusta os valores médios do módulo de elasticidade secante em relação à resistência a compressão. O coeficiente angular da reta de aproximação pode variar de 600 a 740 vezes a resistência à compressão da argamassa;

- As argamassas com resistência à compressão de 20 MPa tiveram um comportamento linear até, aproximadamente, 0,83 da tensão última. Para as argamassas de resistência à compressão de 7,1 MPa e 3,7 MPa, as deformações não-lineares aconteceram quando o nível de tensão atingiu 0,47 e 0,37 da resistência à compressão. Isso pode estar vinculado com a distribuição e tamanho dos vazios internos da argamassa e, por conseqüência, pode afetar o modo de ruptura das amostras. Estudos posteriores devem ser realizados a fim de verificar o tamanho dos vazios e a distribuição, pois poderá auxiliar na interpretação das deformações nãolineares da argamassa;

- A argamassa confinada apresentou um comportamento linear entre o aumento da resistência à compressão e a tensão lateral;

- Notou-se uma significativa redução no coeficiente de Poisson das argamassas, com o aumento das tensões confinantes. Isso pode explicar o aumento do módulo de elasticidade da argamassa confinada e, por conseqüência, levar à compreensão dos fenômenos de ruptura do conjunto unidade-argamassa à compressão.

\section{BIBLIOGRAFIA}

[1] DRYSDALE, R.G., HAMID A.A., "Behavior of concrete block masonry under axial compression”, American Concrete Institute Journal, v. 76, n. 6, pp. 707-721, February 1979.

[2] McNARY, S.W., Basic properties of clay-unit masonry in compression, M.Sc Thesis, University of Colorado, Boulder, CO, Estados Unidos, 1984.

[3] CHEEMA, T.S., KLINGNER, R.E., “Compressive strength of concrete masonry prism”, American Concrete Institute Journal, v.83, n. 1, pp. 88-97, May 1986.

[4] KHALAF, A., HENDRY, W., FAIRBAIN, D.R., "Mechanical properties of material used in concrete blockwork construction”, Magazine of Concrete Research, v. 44, March 1994.

[5] VERMELTFOORT, A.T., Brick-mortar interaction in masonry under pressure, Ph.D. Thesis, Technical. University of Eindhoven, Eindhoven, NL-NB, Nederland, 2004.

[6] MOHAMAD, G., LOURENÇO, P.B.E ROMAN, H.R., "Propriedades mecânicas das argamassas sob compressão triaxial - análise e previsão”, In: Proceedings of the XXXII Jornadas Sulamericanas de Engenharia Estrutural, pp. 2954-2963, Campinas, São Paulo, Maio 2006.

[7] SHRIVE, N.G., "Compressive strength and strength testing of masonry”, In: Proceeding of the 7 IBMAC, Eds. T. McNeilly and J. C. Scrivener, Melbourne, BDRI, pp. 699-710, 1985.

[8] BRITISH STANDARDS INSTITUTION (BSI). BSI-5628, "Code of practice for use of masonry. Structural use of unreinforced masonry”, Part 1, London, December 1992.

[9] AMERICAN SOCIETY FOR TESTING AND MATERIALS, "Standard specification for mortar for unit masonry”, In: Annual Book of ASTM Standards: Chemical-Resistant Nonmetallic Materials; 
Vitrified Clay Pipe; Concrete Pipe; Fiber-Reinforced Cement Products; Mortars and Grouts; Masonry; Precast Concrete: Designation C270, v. 04.05, Pennsylvania, June 1997.

[10] ANÔNIMO (1983), NBR 7211: Agregado para concreto, Rio de Janeiro, ABNT- Associação Brasileira de Normas e Técnicas.

[11] ANÔNIMO (2005), NBR 7211: Agregado para concreto, Rio de Janeiro, ABNT- Associação Brasileira de Normas e Técnicas.

[12] COMITÊ EUROPEU DE NORMALIZAÇÃO. EN 459-1: Cal de construção: Parte 1: Definições, especificações e critérios de conformidade. Instituto Português de Qualidade, 2002.

[13] COMITÊ EUROPEU DE NORMALIZAÇÃO, EN 197-1: Cimento. Parte 1: Composição, especificações e critérios de conformidade para cimentos correntes, Instituto Português de Qualidade, 2001.

[14] BRITISH STANDARDS INSTITUTION (BSI). BSI-1200: Specifications for building sands from natural sources, London, July 1976.

[15] AMERICAN SOCIETY FOR TESTING AND MATERIALS. "Standard specification for aggregate for masonry mortar”, In: Annual Book of ASTM Standards: Chemical-Resistant Nonmetallic Materials; Vitrified Clay Pipe; Concrete Pipe; Fiber-Reinforced Cement Products; Mortars and Grouts; Masonry; Precast Concrete: Designation C144, v. 04.05, Pennsylvania, June 1999.

[16] ANÔNIMO (1982), NBR 7251: Agregado em estado solto: Determinação da massa unitária, Rio de Janeiro, ABNT- Associação Brasileira de Normas e Técnicas.

[17] ANÔNIMO (1987), NBR 9778: Argamassa e concreto endurecidos - Determinação da absorção de água por imersão - Índice de vazios e massa específica, Rio de Janeiro, ABNT- Associação Brasileira de Normas e Técnicas.

[18] ANÔNIMO (2003), NBR 8522: Concreto - Determinação dos módulos estáticos de elasticidade e de deformação e da curva tensão-deformação, Rio de Janeiro, ABNT- Associação Brasileira de Normas e Técnicas.

[19] MOHAMAD, G., Comportamento Mecânico na Ruptura de Prismas de Blocos de Concreto, Tese de M.Sc., Programa de Pós-Graduação em Engenharia Civil - PPGEC/ UFSC, Florianópolis, SC, Brasil, 1998.

[20] KHOO, C.L., A failure criterion for brickwork in axial compression, Ph.D. Thesis, University of Edinburgh, Edinburgh, Scotland, 1972.

[21] ATKINSON, R.H; NOLAND, J.L., ABRAMS, D.P., “A deformation failure theory for stack-bond brick masonry prism in compression”, In: Proceedings of the $7^{\text {th }}$ International Brick Masonry Conference, Melbourne, v. 1, pp. 577-592, February 1985.

[22] HAYEN, R., VAN BALEN, K., VAN GEMERT D., "The mechanical behavior of mortars in triaxial compression”, In: Proceedings of the Arch Bridge IV-Advances in Assessment, Structural Design and Construction, Barcelona, pp. 395-404, November 2004.

[23] OTTOSEN, N.S., “Constitutive model for short-time loading of concrete”, Journal of the Engineering Mechanics Division, ASCE, v. 105, n. 2, pp. 127-141, 1979. 